\title{
Toward the development of consumer-based criteria for the evaluation of assistive devices
}

\author{
Andrew I. Batavia, JD, MS; Guy S. Hammer, BSEE, PE \\ National Rehabilitation Hospital, Rehabilitation Engineering Center, Washington, DC 20010
}

\begin{abstract}
The most important basis for evaluating an assistive device is whether it satisfies the needs of the disabled consumer. However, the factors that consumers consider in determining whether a device meets their needs are not well understood. This preliminary study applied a small focus group process to identify and prioritize factors used by long-term users of assistive technology in assessing their devices. A modified version of the Delphi Method was applied to two groups of long-term users-a Panel of Consumer Experts with Mobility Impairments and a Panel of Consumer Experts with Sensory Impairments. In total, the panels identified and prioritized 17 general factors for 11 types of assistive technologies. This study constitutes an initial step toward the development of design, engineering, and selection criteria based on the specific concerns of consumers.
\end{abstract}

Key words: Delphi Method, disabled consumer, evaluation of assistive devices, mobility impairments, sensory impairments.

\section{INTRODUCTION}

The literature on rehabilitation engineering is replete with technical descriptions and analyses of a broad array of assistive devices that are intended to enhance the lives of persons with disabilities. Such devices range from manual wheelchairs to motorized wheelchairs to highly

Address all correspondence and requests for reprints to: Andrew Batavia, 700 7 th Street SW, \#813, Washington, DC 20024

Andrew I. Batavia is Associate Director for Health Services Research, National Rehabilitation Hospital Research Center and an adjunct Assistant Professor, Georgetown University School of Medicine. He currently holds an appointment as a 1990-1991 White House Fellow.

Guy Hammer is a Consulting Rehabilitation Engineer and Manager of the Biomedical Applications Program, Strategic Defense Initiative Organization. sophisticated robotics and augmentative communication devices. The literature includes articles on standards developed for evaluating the structural integrity of those devices, as well as other aspects of engineering design (4). However, the literature is deficient in one fundamental aspect. It contains no comprehensive analyses of the ultimate criteria by which such devices must be judgedthe needs of the disabled consumer.

There has been valuable research on the general attitudes of disabled persons toward their assistive devices (12). There also has been research on the reasons for the abandonment of assistive devices by persons with disabilities $(7,14)$. However, these studies basically address issues of how assistive devices are regarded by consumers, and how and why assistive devices are purchased and abandoned; they do not focus on how devices should be designed, manufactured, and selected to enhance the likelihood that they will not be abandoned. While the results of these studies have certain normative implications, they do not provide a comprehensive set of guidelines for designers, manufacturers, prescribers, payors, and consumers (1).

Until recently, there has been relatively little research conducted from the perspective of the consumer on the assessment of assistive technology, and there have been no attempts to develop comprehensive consumer-based criteria for evaluating assistive devices. In 1986, Hyman, Miller, and O'Brien contended that:

the present dissemination of rehabilitation technology is limited in part by poor communication channels and uneven evaluations dominated by anecdotal self-assessment by device developers (6).

Increasingly, however, professionals in the field of 
Journal of Rehabilitation Research and Development Vol. 27 No. 4 Fall 1990

assistive technology have attempted to address this problem by meeting with experienced users of assistive devices to discuss their experiences and better assess their needs and preferences. In short, there has been recognition that consumer input is important. A few innovative researchers have developed formalized protocols to assess consumer needs, primarily for purposes of clinical evaluation and prescription of devices. For example, researchers at MIT and Tufts developed a computer-based system that guides prospective users of augmentative communication technology through a series of assessment questions, and thereby guides the clinician in assisting the user to select an appropriate communication device $(2,3,9,10,11)$.

While such individualized approaches appear valuable in guiding the clinical prescription of devices, they are less useful for broader design and policy applications that affect large numbers of users. For these purposes, a better approach is to develop criteria for assessing assistive devices based upon factors that are most important to consumers. In developing and applying such criteria, designers and manufacturers would derive greater insight into whether their products will be accepted and used by disabled persons. Consumers, payors, vocational rehabilitation counselors, prescribers, and other persons involved in the purchase of assistive devices would gain insight into which products to purchase.

\section{THE PROBLEM}

As observers of the use of assistive devices by persons with disabilities, the authors have recognized a common pattern of adoption and abandonment of such devices, particularly by persons who are recently disabled or who are new users of a device. The pattern typically is as follows:

1) the disabled individual is provided an assistive device (e.g., motorized wheelchair) through a clinicallyaided or personal selection process;

2) the individual uses the device and recognizes that it is inadequate to meet his or her needs for one or more reasons, even after attempted modifications;

3) the individual either continues to use the device, remaining dissatisfied with it until it is no longer usable, or abandons the device at an early stage; and,

4) the individual then chooses another device that satisfies the needs the previous device failed to satisfy (but often fails to meet other needs).

This pattern often is repeated two or three times before the individual finally receives a device that adequately meets his or her needs.

It appears that one reason for this pattern is that the disabled consumer (or the person who chooses the device on behalf of the consumer) often is not adequately aware of his or her own needs as they relate to assistive devices. This is particularly true of persons who are recently disabled. Newly-disabled individuals need to become familiar with the changed needs of their bodies and to learn the relationship between these needs and the technologies that can help them compensate functionally for their physical limitations. In the meantime, without adequate guidance, these individuals often are subject to dissatisfaction and frustration, and their financial resources often are wasted (8).

From the standpoint of public policy, the individual's dissatisfaction, frustration, and economic loss are multiplied by the thousands of people who experience similar problems with their assistive devices. Private insurers and provider organizations, in their roles as buying agents for consumers, serve as mass purchasers of assistive devices. Federal, state, and local government agencies also invest heavily in assistive devices, both as developers of technologies and as large purchasers of assistive devices. At a societal level, resources are wasted and opportunities are lost when such investment and purchasing decisions are directed poorly at the needs of consumers.

However, lessons can be learned from the past purchasing mistakes of individual consumers, prescribers, insurers, provider organizations, and government agencies. Implicit in each disabled person's procurement, disillusionment, and abandonment of a device is a learning process. Over time, as a result of each positive and negative experience with a type of assistive device, disabled users develop a better understanding of their assistive technology needs. In effect, the individual eventually develops a set of evaluation factors by which to judge the extent to which various technologies will meet his or her needs (1).

Yet, there also is a tendency for individuals to forget the factors that they have developed over time, or to forget to apply the factors in assessing and adopting new and different devices. This is, in part, because few consumers take the time to write the factors down, and thereby to make them explicit for the purpose of making future decisions. In addition, because insurers, government agencies, and other large purchasers of assistive devices typically are not exposed directly to the individual's bad experiences with a device and the consequent learning process, they seldom derive the benefit of the factors developed by the individual.

A comprehensive list of the factors used by consumers in assessing assistive devices is not currently available. By 
deriving a better understanding of these factors, and converting them to usable design, engineering, and selection criteria, it is possible to enhance the likelihood that decisions will be made more systematically and in a more informed manner. A wide variety of decision makers, including designers, manufacturers, prescribers, payors, and consumers, would benefit from such criteria. Moreover, by using explicitly-stated criteria, rehabilitation providers and other professionals who address the needs of disabled persons can facilitate the learning process of their patients and other potential users of assistive devices.

The purpose of this study was to identify and prioritize the factors used by long-term users in assessing their assistive devices, thus providing the basis to develop criteria that will be helpful in the design, manufacture, and selection of devices. If the criteria ultimately developed prove to be valid predictors of consumer acceptance and satisfaction with assistive devices, and if accepted by large numbers of consumers and professionals, they are likely to reduce the level of technology abandonment and dissatisfaction and help preserve the scarce resources of individuals, insurers, government, and society in general.

\section{THE STUDY}

The basic premises of this study were that: $a$ ) disabled persons who use assistive devices over a period of time develop a set of factors for selecting or rejecting new technological devices, based on their past experiences with such devices; $b$ ) these factors can be identified and prioritized; and, c) these factors may provide valuable insight into developing criteria to be used in designing, manufacturing, and selecting assistive devices. In short, the factors used by persons with disabilities for assessing the value of assistive devices can be identified, stated explicitly, operationalized, and used to enhance the likelihood that assistive devices will be accepted in use.

\section{Methodology}

A small focus group process based on a modified version of the Delphi Method-a research procedure designed to facilitate consensus-building among small groups of experts (13) - was used to identify and prioritize factors used by consumers for evaluating a variety of types of assistive technology. It should be noted that these factors cannot serve directly as design, engineering, or selection criteria. The term "criterion," as used by engineers, refers to a clearly-defined, typically quantifiable standard by which to make an engineering decision. However, it is expected that the factors identified through this study eventually will contribute to the development of more formalized engineering criteria.

The conventional Delphi Method entails a three-stage process in which numerous experts respond independently to three mailed survey questionnaires. In the first stage of the Delphi, the experts are asked through an open-ended questionnaire to specify the issues they consider to be the most important with respect to the topic under consideration. The issues specified by respondents are then reviewed, analyzed, and compiled in a list of mutually exclusive issues. In the second stage, respondents are provided the list of issues identified in Stage One, and asked to rank the issues in order of importance. In the third and final stage, respondents are provided the aggregated rankings of the group from Stage Two and, considering the priorities of the group, asked to complete one final rank-ordering of the issues. This stage is essential to the process of consensus-building among the experts (13).

In the current study, a modified form of the Delphi Method using focus groups was utilized to enhance the efficiency of the Delphi process and to take advantage of group interaction among disabled participants. Two focus groups of long-term users of assistive devices were assembled to identify and prioritize factors based upon their experiences. A Panel of Consumer Experts with Mobility Impairments (hereafter, the "Mobility Panel") consisting of six persons with disabilities that include cerebral palsy, muscular dystrophy, spinal cord injury, and post-polio was convened at the first meeting of the study. A Panel of Consumer Experts with Sensory Impairments (hereafter, the "Sensory Panel"), which included three persons who are deaf, one person who is hard-of-hearing, and two persons who are blind, was convened two weeks later at the second meeting. All three stages of the process were conducted at each meeting (1).

Prior to convening the panels, the principal investigators developed an initial listing of evaluation factors based upon their experiences in assessing assistive devices. One investigator (Batavia) is a professional researcher in the disability field who has been a user of assistive devices for 16 years, and who has served as a tester of such technologies at two major rehabilitation centers. The other investigator (Hammer) is a rehabilitation engineer who has dedicated much of his career to the assessment of rehabilitation and medical technologies. Together, the investigators developed and defined the following 12 factors: Affordability, Consumer Repairability, Dependability, Durability, Ease of Assembly, Ease of Maintenance, Learnability, Operability, Personal Acceptability, Physical 
Journal of Rehabilitation Research and Development Vol. 27 No. 4 Fall 1990

Comfort, Physical Security, and Supplier Repairability. These factors, and five additional factors that were added by the panels during Stage One of the Delphi, are defined below.

In Stage One of the modified Delphi, panel members were asked to identify the factors they use in assessing their own technologies. For each of the areas of technology assessed (which are discussed below), panelists were asked to develop a list of factors for evaluating assistive devices in that area. They were then asked to compare their factors with those developed by the principal investigators to determine whether additional factors should be added to the initial list. The Mobility Panel added three factors: Compatibility, Effectiveness, and Flexibility. The Sensory Panel added two additional factors: Portability and Securability. The initial list of factors developed by the investigators was modified accordingly, to develop a comprehensive set of consumer-based factors.

In Stage Two of the process, the list of factors agreed upon by the group was randomized (to avoid systematic bias), and panel members were asked to indicate their priorities for the factors in order of importance. They were instructed to assume that the technology assessed meets an average level of performance for each of the factors (e.g., an average level of dependability, durability, repairability, etc.), and to indicate the order in which the factors would be important to them for that technology.

In other words, the panels considered the full range of possible levels of a factor from very low to very high for each type of device assessed, and assumed an average level for that factor in comparing it with average levels of the other factors. For example, if the panel member felt that an average level of wheelchair durability is acceptable, but an average level of dependability is not, the individual would choose dependability over durability. Wheelchair dependability is more important to that panel member than wheelchair durability.

Thus, for each technology assessed in Stage Two, panel members placed a " 1 " next to the factor of highest priority, a " 2 " next to the second highest factor, etc., through "17" for the factor that received the lowest priority. In Stage Three, panel members verbally explained the rationale underlying their prioritizations in Stage Two to their panels, and then individually re-prioritized the factors, taking into consideration the positions of their fellow panel members.

The Mobility Panel prioritized only 15 of the 17 factors that were ultimately identified because it met prior to the Sensory Panel, which later identified the 2 additional factors. For purposes of comparing the responses of the Mobility Panel with those of the Sensory Panel in Stages
Two and Three, the Sensory Panel was asked to prioritize only the 15 factors considered by the Mobility Panel. They later were asked to prioritize all 17 factors, including those that were not identified and prioritized by the Mobility Panel.

\section{Initial development of factors}

Prior to the panel meetings, the investigators developed an initial list of factors relevant to the selection and evaluation of assistive devices, based on their experiences in evaluating devices and in assisting disabled persons to assess their devices. Anecdotal evidence from patients at rehabilitation hospitals and other disabled persons who use assistive devices suggested that the general considerations used by disabled persons in assessing their devices appear to be fairly universal. The considerations relate to the following experiences:

- difficulty in learning to use the device;

- difficulty in using the device;

- difficulty in maintaining the device;

- difficulty in repairing the device;

- interference with the individual's lifestyle and social activities;

- physical discomfort in using the device;

- physical danger associated with the device;

- social and/or psychological discomfort in using the device; and,

- inability to afford the device, its repair and maintenance.

The investigators recognized that this list was not necessarily exhaustive of all categories of concerns raised by consumers of assistive devices. Further, the concerns listed were not developed in sufficient detail to discern specific evaluation factors or criteria, or to otherwise be of substantial value to purchasers of assistive devices. However, the list provided an initial point of departure for the investigators to develop an initial set of 12 factors based upon the stated concerns of consumers. These factors were later confirmed and supplemented with five additional factors by the panels during Stage One of the focus group process.

\section{Selection of panel members}

An attempt was made to obtain participation by persons with a variety of disabilities on the panels. Panel members were selected on the basis of three criteria. A panel member had to: 1) have a physical disability (i.e., either a mobility impairment or a sensory impairment); 2) be a long-time user (at least 5 years) of one or more assistive devices for persons with his or her disability; and, 3 ) have 
well-developed analytical and communicative skills necessary to identify, prioritize, and convey his or her factors for assessing technology.

The investigators asked leaders in the disability community for their suggestions on the selection of panel members who meet these criteria. It must be stressed that the persons who participated in the panels are not necessarily representative of the disabled population (or even of disabled persons who are long-term users of assistive devices). For this preliminary study, no attempt was made to obtain a statistically representative sample of the disabled population. The panel members are, however, a handpicked group of analytical and articulate long-term users of assistive devices with a variety of disabilities. As such, they can provide valuable insight into the evaluation factors used by one group of disabled persons whose members have given careful thought to how assistive devices should be designed, manufactured, and selected.

\section{The Panel of Consumer Experts with Mobility Impairments}

The members of the Mobility Panel included:

- a 38-year-old female with muscular dystrophy who has been disabled since birth and uses a motorized wheelchair and a hydraulic bath lift;

- a 45-year-old female with traumatic spinal cord injury (C4-5) who has been disabled for 18 years and uses a motorized wheelchair, wrist splints, a reclining bench, a urinary drainage system, a dictating machine, a speaker phone, and a wheelchair-accessible van;

- a 51-year-old male with post-polio syndrome who has been disabled for 34 years and uses a manual wheelchair and a motorized wheelchair;

- a 34-year-old male with spinal cord injury (C1-2) who has been disabled for 15 years and uses a voice recognition typing system and a sip-and-puff motorized wheelchair;

- a 38-year-old female with muscular dystrophy who has been disabled since birth and uses a motorized wheelchair, a Hoyer lift, a hospital bed, an accessible van, and a stick for pushing elevator buttons; and,

- a 31-year-old male with cerebral palsy who has been disabled since birth and uses a motorized wheelchair and a speech board.

\section{The Panel of Consumer Experts with Sensory Impairments} The members of the Sensory Panel included:

- a 30-year-old female who has been partially deaf for 22 years and who uses hearing aids, an FM Loop amplification system, a TDD telephone, a vibrating alarm clock, a captioning decoder, an amplified handset telephone, and a flashing alert system;

- a 43-year-old male who has been legally blind for 36 years and who uses a talking book player, a Talkman, a tape player, a talking computer, and a "talking system" for sailing;

- a female (age not disclosed) who has been legally blind for 17 years and hearing-impaired for 2 years, and who uses a white cane, a manual wheelchair, a talking clock, and an amplified telephone;

- a 69-year-old male who has been hard-of-hearing for 12 years and who uses hearing aids and other amplification devices;

- a 44-year-old female who has been totally deaf for 40 years and who uses a TDD telephone, a captioning decoder, a vibrating alarm clock, and a light flasher for the telephone; and,

- a 46-year-old male who has been deaf since birth and who uses a home flashing system, a TV captioning decoder, a TDD telephone, and a vibrating alarm clock.

In addition, two other persons who are totally blind were invited to participate on the Sensory Panel, but failed to show up at the panel's meeting and were therefore not included in the study.

\section{Selection of technologies}

Rather than select specific assistive devices (i.e., products) to evaluate, the researchers selected several broad areas of technology, such as wheelchairs, telephone systems, environmental control systems, and locational systems. In this way, each panel member could contemplate his or her specific needs with respect to an assistive device appropriate for that person within the general area of technology being assessed. For example, under the general area of telephone systems, a person with quadriplegia might consider a speakerphone, a person who is totally deaf might consider a TDD, and a person who is hard-of-hearing might consider a phone with amplification capabilities. Because panel members were not asked to assess devices that are not applicable to them, they were better able to make valid assessments. Because they were not asked to assess specific manufactured products, they were not unduly biased by specific product strengths and weaknesses.

\section{Technologies for Persons with Mobility Impairments}

The technologies assessed by the Mobility Panel were:

- motorized wheelchair-a non-manual wheelchair powered by batteries; 
Journal of Rehabilitation Research and Development Vol. 27 No. 4 Fall 1990

- typing system-a mechanism for entering data on a computer or other device to receive or store data;

- robotic arm-a device that robotically performs functions of the human arm and hands;

- environmental control system-a device that assists the disabled individual to control his or her environment by turning on and off lights and other appliances; and,

- telephone system-a device for communicating over extended distances.

\section{Technologies for Persons who are Blind}

The technologies assessed by the blind persons on the Sensory Panel were:

- type reader (e.g., Kurzweil machine)-a device that verbally reads written text using synthesized speech;

- recording system-a device that records or transcribes and retrieves information (verbally or otherwise); and,

- locational system-a device that provides information on one's geographic location.

Initially, there was some confusion among the blind panel members as to whether they were being asked to evaluate a locational system (which provides information on where one is geographically-such as street or avenue), or an orientation system (which provides information on terrain, curb cuts, and other physical impediments). The investigators clarified that the locational system was to be assessed. In response to the concern by blind panel members that locational systems are not as important as orientation systems to most blind persons, the investigators assured the panel that, in studying the technologies that were assessed, this study does not in any way mean to endorse any particular technology.

\section{Technologies for Persons who are Deaf}

The technologies assessed by the hearing-impaired and deaf persons on the Sensory Panel were:

- alerting system-a device that informs a hearing-impaired person of danger or other external stimulus (typically using lights or vibrations);

- phone system-a device for communicating over extended distances; and,

- speech recognition system-a device that transforms spoken words to another form understandable by a person who cannot hear.

\section{Findings}

The findings of this study relate to: 1$)$ the factors identified by the panels; and, 2) the prioritization of the factors by the panels. They are as follows:

\section{The Factors Identified}

Round one of the modified Delphi Method identified 17 factors - the 12 factors initially identified by the investigators and verified by the panel members, plus 5 additional factors provided by the panel members. The 17 factors are presented in alphabetical order below, along with their definitions. The factors are further operationalized through specific sub-factors provided by the panel members in round one. The sub-factors are presented in the form of questions that a consumer or other purchaser of assistive devices might ask in making an informed decision. Although the questions presented are not exhaustive of all issues that should be considered within an evaluation factor, they do provide a sample of relevant and important issues to be raised in designing, manufacturing, or selecting a device.

1. Affordability - the extent to which the purchase, maintenance, and/or repair of the device causes financial difficulty or hardship to the consumer.

- What is the price of the device?

- Are there any hidden costs (e.g., installation costs)?

- What are the likely costs of maintenance and repair?

- Are the total costs of the device, including price, maintenance, repair, and any other costs within the consumer's means? Are they covered by public or private insurance (or other financing programs)? What share of the costs does the consumer have to pay out-of-pocket?

- Are there any warranties on the device, and how do they affect the costs to the consumer?

2. Compatibility-the extent to which the device will interface with other devices currently and in the future.

- Does the device operate independently or does it need to interface with other devices?

- If it needs to interface with other devices, what are those devices? Is it currently compatible with such devices in the market?

- Is the device likely to become obsolete in the near future due to compatibility problems with devices now being developed or contemplated?

3. Consumer Repairability - the extent to which the average consumer (or his or her personal assistant) can repair the device if broken, including whether special repair equipment is needed. 
- What types of repairs can the consumer (or assistant) reasonably be expected to do, and what types of repairs must be conducted by an expert?

- What, if any, education/training is required for the consumer or assistant to repair the device?

- What, if any, special equipment is required to make any such repairs?

- Does the unit have special design features (e.g., plug-in modules) that can reduce the difficulty of repairs? Have any spares been provided for this purpose?

4. Dependability - the extent to which the device operates with repeatable/predictable levels of accuracy under all conditions of reasonable use.

- Is the device dependable? What has been the prior breakdown history of these types of devices? Where was such information obtained?

- Is any special room environment required (e.g., heating, cooling, dust-free)? Will low or high humidity cause problems? If so, what percentage of relative humidity is acceptable? Is the unit affected adversely by electromagnetic interference or power line "noise?" If so, by what levels?

- What problems can arise if the equipment is not turned on and operated according to prescribed operating instructions? Can any permanent damage occur due to an improper action? If so, what actions will result in what kinds of damage?

- Will the device remain dependable under repeated use?

5. Durability - the extent to which the device will continue to be operable for an extended period of time.

- What is the expected life of the device (i.e., how long will the device last before it can be expected to have significant dependability problems requiring frequent and expensive repairs)?

- What level of care and maintenance is necessary for the device to last throughout (and beyond) its expected life?

6. Ease of Assembly - the extent to which the consumer (or his or her personal assistant) can easily assemble the device upon receiving it, including whether it is packaged conveniently.

- Will the supplier assemble and/or install the device?

- If not, what portion of the assembly or installation can the consumer (or personal assistant) reasonably be expected to do? Is a technician or engineer required for initial assembly or installation?

- Are instructions for assembly and/or installation included in the manual? Are the instructions complete, concise, clear, and easy to follow (i.e., a logical step-by-step procedure)?

- Are any special tools required for assembly, installation or start-up? Is any test equipment (e.g., computer, multimeter, oscilloscope) required for start-up or calibration?

- Are other kinds of devices/furniture required to complete the system (e.g., special tables, wall mountings)? If so, will the supplier provide these?

7. Ease of Maintenance-the extent to which the consumer (or his or her personal assistant) can easily maintain the device to keep it operable and safe, including whether it is easy to conduct all required maintenance, cleaning, and infection control procedures.

- Is maintenance easily handled by the consumer (or personal assistant)?

- How often are maintenance routines necessary? Are maintenance record forms provided? Are they adequate?

- Are operation and maintenance manuals included with the unit? Does the instruction book spell out all maintenance routines to be followed? Are they effective? If not, in what ways are they deficient?

- Are there adequate precautions for sterilization of the device (e.g., gas or steam) to prevent infection? What are the appropriate methods/chemicals for disinfection? Are specific cleaning procedures required?

8. Effectiveness - the extent to which the functioning of the device improves the consumer's living situation, as perceived by the consumer, including whether it enhances functional capability and/or independence.

- What does the manufacturer of the device claim the device will do? Does the device do what is claimed?

- Does the device meet the specific needs of the consumer? If so, what specific needs are met and in what way? In meeting these needs, are other important needs compromised?

9. Flexibility - the extent to which the device is provided with available options from which the consumer may choose.

- What options are available with the device?

- Are these options important to the consumer? What is the cost of these options?

10. Learnability - the extent to which the consumer, upon initially receiving the device, can easily learn to use it and can start using it within a reasonable period of time once assembled, including whether specialized training is required. 
- How long will it take for the consumer to learn to use the device effectively?

- Are the operational instructions clear in terms of turning on the equipment, making any preliminary adjustments that are required, and allowing the equipment to warm up?

- Is specialized training required? If so, how much training, and is it included in the price of the product?

- How long should it take to run through all start-up and diagnostic routines that need to be done the first time? Can the consumer do these or must he or she have assistance?

11. Operability - the extent to which the device is easy to operate and responds adequately to the consumer's operative commands, including whether controls and displays are accessible and whether start-up time for each use is excessive.

- Are the controls and displays easily accessible and usable?

- How responsive are the visual displays in terms of viewing angles, colors, and shapes? How responsive are audible tones/alarms in terms of harshness, loudness, length, frequency, and understandability (e.g., speech or synthesized speech)?

- What cyclical routines must be followed each day as the unit is used in the prescribed fashion? Does it need constant adjustment and/or excessive care in everyday use? Are there indications that the equipment is ready to use (e.g., meter readings, lights on or off, signals)?

- Are there any tests or readjustments that need to be made as the equipment is used during the initial warm-up/ use phase?

- What portion of the turn-on/start-up routines must be followed each time the device is used? Is the start-up time excessive?

12. Personal Acceptability-the extent to which the consumer is psychologically comfortable when using the device in public (or in private), including whether the device is aesthetically attractive.

- Would the consumer be embarrassed by any aspect of the device (e.g., physical appearance or unusual sounds)?

- Is the design of the device compatible with the consumer's personality and lifestyle?

13. Physical Comfort-the extent to which the device causes physical pain or discomfort to the consumer.

- Does the device cause pain or discomfort? Does it make noises that are irritating to the ear or physical sensations that are irritating to the skin?

- Does the consumer have to strain physically in using the device? Is it physically compatible with the consumer's body?

- Does the device have special features to enhance comfort (e.g., a special seating system or shock absorbers in the case of a wheelchair)?

14. Physical Security - the extent to which the device is likely to cause physical harm, including bodily injury or infection, to the consumer.

- Is the device safe to operate? What are its safety features (e.g., emergency brakes)?

- Are there any aspects of the device that are likely to cause physical damage or severe irritation, such as pressure sores? Does it disrupt internal physiologic functions (e.g., normal flow of blood or urine)?

- Is the device likely to cause infection or other adverse physiologic reaction?

15. Portability - the extent to which the device can readily be transported to and operated in different locations, including whether the length of battery charge and the size and weight of the device permit physical relocation.

- Can the device be transported easily to different physical and geographical locations without undue difficulty? Can it be carried comfortably or (in the case of long distance travel) transported in a car, train, or airplane?

- If the device is powered by a battery, what is the length of the battery charge?

- If the device depends upon an external power supply or other hook-up, will such hook-up be available in other locations? Can it be adapted to hook up in different locations?

16. Securability-the extent to which the device can easily be kept within the physical control of the consumer to reduce the likelihood of theft or vandalism.

- Is the device easily secured so that it is difficult to steal?

- Does it have any special features to enhance security?

17. Supplier Repairability-the extent to which a local supplier or repair shop can repair the device within a reasonable period of time, including whether replacement parts are readily available and whether the manufacturer must conduct repairs.

- If the device cannot be easily repaired by the consumer (or personal assistant), must it be returned to the manu- 
facturer or distributor? What are the likely turn-around times of the most prevalent problems?

- If the device typically can be repaired locally by a supplier or repair shop, what is the likely turn-around time? Are replacement parts readily available? Does it have any "built-in" diagnostic routines for fault determination?

- Is a "hot-line" available to allow easy access to the manufacturer/distributor? If it is available, is the manufacturer/distributor responsive to calls?

\section{The prioritizations}

The final rankings of the factors by the two panels are provided in Table 1. It indicates that effectiveness, affordability, operability, and dependability are, on average, the four most important factors for all technologies assessed. Ease of assembly is regarded as relatively unimportant by both panels across all technologies assessed. The rankings of the other factors depend largely on the specific technology being assessed. For example, personal acceptability is regarded by the mobility panel as a fairly important criterion with respect to wheelchairs (i.e., ranked fifth), but is relatively unimportant with respect to typing systems and environmental control systems (i.e., ranked eleventh and thirteenth, respectively). One likely explanation for this is that these individuals regard their wheelchairs as part of their physical appearance, while they regard typing systems and environmental systems primarily for their utilitarian value.

A perusal of Table 1 suggests that there is substantial consistency among the rankings of the three disability groups in the two panels. In assessing consistency between the two panels, average rankings of each factor were calculated for each panel to determine each panel's aggregate rankings, and the Pearson product-moment correlation was applied to compare the aggregate rankings between panels. The Pearson product-moment correlation between the rankings of the mobility panel and the sensory panel is 0.82, suggesting a high level of consistency in rankings (although the statistical reliability of this finding is not high, due to small sample size).

\section{DISCUSSION}

A blind member of the sensory panel observed that, without using a particular product over an extended period of time, he has great difficulty in assessing whether it will meet his needs. He contended, therefore, that the most efficient test of whether to purchase a device is whether it has survived and flourished in the general market (in which nondisabled and disabled persons purchase products). A consensus emerged among the sensory panel that, to the extent that a device is testable in the general market (such as a dictating machine), the market provides the best means by which to evaluate a device. A likely explanation is that the factors most important to disabled consumers may be the same as the factors that are most important to consumers generally.

However, the market test is not available for many products needed by persons with disabilities, because many assistive devices for disabled persons are not purchased in the general market. This includes "orphan devices" that have very small markets because they address needs specific to certain disabilities that occur infrequently in the general population (5). The markets for products that are not specifically applicable to nondisabled persons often are too small to "police" the quality of a product adequately. While the market for motorized wheelchairs may now be large enough to assess product quality, the markets for specialized wheelchairs, robotic arms, environmental control systems, speech recognition systems, and locational systems probably are not.

Therefore, for those assistive devices that are not adequately tested in the general market, normative evaluation criteria are needed to guide selection, design, and manufacturing processes. This preliminary study offers the rudiments of a theory of technology evaluation, and a preliminary set of factors with which to develop evaluation criteria. The basic premises of a consumer-based evaluation theory are that: 1) the consumer-the disabled person who uses an assistive device-must be the ultimate evaluator of whether a device is satisfactory; and, 2) the consumer who has used a device for an extended period of time is in the best position to offer factors to be considered in developing normative evaluation criteria for the device.

It must be stressed that this study is preliminary in nature. It used a very small sample of consumers who are not necessarily representative of the population of longterm users of assistive devices, and it did not test the validity and reliability of the evaluation factors identified 
Journal of Rehabilitation Research and Development Vol. 27 No. 4 Fall 1990

Table 1.

Final rankings of factors by panels.

\begin{tabular}{|c|c|c|c|c|c|c|c|c|}
\hline & \multicolumn{5}{|c|}{ Mobility Technologies } & \multicolumn{3}{|c|}{ Blind Technologies } \\
\hline & $\begin{array}{l}\text { Wheel- } \\
\text { chair }\end{array}$ & $\begin{array}{l}\text { Typing } \\
\text { System }\end{array}$ & $\begin{array}{c}\text { Robotic } \\
\text { Arm }\end{array}$ & $\begin{array}{c}\text { Environ. } \\
\text { Control }\end{array}$ & $\begin{array}{l}\text { Phone } \\
\text { System }\end{array}$ & $\begin{array}{c}\text { Type } \\
\text { Reader }\end{array}$ & $\begin{array}{l}\text { Recording } \\
\text { System }\end{array}$ & $\begin{array}{c}\text { Orientat. } \\
\text { System }\end{array}$ \\
\hline Effectiveness & 1 & 2 & 1 & 1 & 1 & 2 & 2 & 2 \\
\hline Affordability & 4 & 5 & 4 & 6 & 6 & 1 & 1 & 1 \\
\hline Operability & 2 & 1 & 2 & 2 & 2 & 5 & 7 & 10 \\
\hline Dependability & 3 & 4 & 3 & 3 & 3 & 3 & 3 & 6 \\
\hline Portability & $*$ & $*$ & $*$ & * & * & 7 & 4 & 3 \\
\hline Durability & 8 & 8 & 8 & 7 & 7 & 4 & 5 & 11 \\
\hline Compatibility & 13 & 3 & 6 & 4 & 5 & 6 & 6 & 13 \\
\hline Flexibility & 7 & 6 & 5 & 5 & 4 & 11 & 9 & 15 \\
\hline Ease of maintenance & 6 & 9 & 11 & 9 & 11 & 8 & 8 & 8 \\
\hline Securability & * & $*$ & $*$ & $*$ & $*$ & 13 & 11 & 7 \\
\hline Learnability & 14 & 7 & 10 & 11 & 10 & 9 & 16 & 14 \\
\hline Personal acceptance & 5 & 11 & 7 & 13 & 9 & 15 & 15 & 12 \\
\hline Physical comfort & 10 & 13 & 13 & 14 & 8 & 12 & 13 & 9 \\
\hline Supplier repair & 9 & 10 & 12 & 8 & 12 & 10 & 10 & 16 \\
\hline Physical security & 11 & 15 & 9 & 10 & 15 & 17 & 17 & 4 \\
\hline Consumer repair & 12 & 12 & 14 & 12 & 13 & 14 & 12 & 5 \\
\hline Ease of assembly & 15 & 14 & 15 & 15 & 14 & 16 & 14 & 17 \\
\hline
\end{tabular}

*These factors were identified by the sensory panel at the second meeting, and were not ranked by the mobility panel.

and prioritized. Therefore, the study's results should not yet be generalized to the broader disabled population. Additional research must be conducted to test the results of this study.

First, it would be valuable to determine the relative weights of each of the identified evaluation factors, because this study considered only the ordinal ranking of factors. Second, studies are needed to assess the validity and reliability of the prioritized factors using a large, representative sample of long-term users of assistive devices. Third, if the rankings of the factors are valid and reliable, formal evaluation criteria must still be developed from them. Finally, if evaluation criteria are developed, it will be useful to develop a protocol for training recently-disabled persons to use the criteria in making purchasing decisions, and to test the value of the criteria in making such decisions.

Whether or not such research is conducted, it is essen- tial that designers, engineers, manufacturers, prescribers, payors, and others who are involved in issues of assistive technology explicitly recognize and address the factors that are important to consumers in selecting their assistive devices. Failure to consider such factors is likely to result in the continued abandonment of devices by disabled persons, and the continued dissatisfaction, frustration, and economic waste associated with such abandonment.

\section{ACKNOWLEDGMENTS}

The authors wish to thank the National Institute on Disability and Rehabilitation Research (NIDRR) for funding this study through the National Rehabilitation Hospital Rehabilitation Engineering Center (NRH-REC) on the Evaluation of Technology. James Reswick, ScD, former Acting Director of NIDRR, 
Table 1 .

Final rankings of factors by panels (continued).

\begin{tabular}{|c|c|c|c|c|}
\hline \multicolumn{4}{|c|}{ Deaf Technologies } & \\
\hline $\begin{array}{c}\text { Alert } \\
\text { System }\end{array}$ & $\begin{array}{l}\text { Phone } \\
\text { System }\end{array}$ & $\begin{array}{l}\text { Speech } \\
\text { Recog. }\end{array}$ & $\begin{array}{l}\text { Average } \\
\text { Ranking }\end{array}$ & \\
\hline 1 & 1 & 1 & 1.36 & Effectiveness \\
\hline 2 & 2 & 2 & 3.09 & Affordability \\
\hline 5 & 3 & 3 & 3.82 & Operability \\
\hline 4 & 5 & 5 & 3.82 & Dependability \\
\hline 6 & 4 & 8 & 5.33 & Portability \\
\hline 3 & 6 & 6 & 6.64 & Durability \\
\hline 10 & 7 & 4 & 7.00 & Compatibility \\
\hline 8 & 9 & 7 & 7.82 & Flexibility \\
\hline 7 & 10 & 9 & 8.73 & Ease of maintenance \\
\hline 11 & 12 & 14 & 11.33 & Securability \\
\hline 14 & 11 & 10 & 11.45 & Learnability \\
\hline 13 & 14 & 13 & 11.55 & Personal acceptance \\
\hline 17 & 8 & 11 & 11.64 & Physical comfort \\
\hline 16 & 16 & 12 & 11.91 & Supplier repair \\
\hline 12 & 13 & 16 & 12.64 & Physical security \\
\hline 15 & 17 & 15 & 12.82 & Consumer repair \\
\hline 9 & 15 & 17 & 14.64 & Ease of assembly \\
\hline
\end{tabular}

deserves particular credit for support of this study. We also thank Gerben DeJong and Thomas Burns for their support; Jessica Scheer, Cheryl Nicholson, Pat Van Sickle, Cynthia JohnsonTurner, and Tilmon Bannister for their assistance; and Lori Fields and Susie Prior for their excellent sign language interpreting services. We particularly want to thank Diana Elmes, James Dickson, Mickey Fields, Judith Gilliom, Richard Heddinger, Karen Jackson, Julius Kopit, Blossom Medina, Mary Jane Owen, Richard Pilgrim, Bob Williams, and Linda Wilson, who contributed their expertise to this study.

\section{REFERENCES}

1. Batavia AI, Hammer G: Consumer criteria for evaluating assistive devices: Implications for technology transfer. In Proceedings of the 12th Annual RESNA Conference, New Orleans, 194-195, 1989.
2. Goodenough-Trepagnier C, Rosen MJ: Assessment of need and prediction of benefit in prescription of communication devices for the nonvocal. In Proceedings of the 8th Annual IEEE EMBS Conference, Fort Worth, 1986.

3. Goodenough-Trepagnier C, Rosen MJ: Quantification of relative importance of communication needs. In Proceedings of the 10th Annual RESNA Conference, San Jose, 151-153, 1987.

4. Hammer GS: Orphan devices: Unwanted products from unneeded research or the foundation for future clinical engineering successes? In Proceedings of the 9th Annual IEEE EMBS Conference, Boston, 1987.

5. Hammer GS: An evaluation protocol for external functional electrical stimulation systems. In Proceedings of the 9th Annual IEEE EMBS Conference, Boston, 1987.

6. Hyman WA, Miller GE, O'Brien EM: Evaluation of rehabilitation devices. In Proceedings, ICAART ' 88 , Montreal, 188-189, 1988. 
7. Lifchez R, Leiser L, Pendleton HM, Davis C: Technology for the living environment. In Technology for Independent Living-Proceedings from 1981 Workshops on Science and Technology for the Handicapped, AAAS, 1983.

8. Reswick JB: Technology-An unfilled promise for the handicapped. Med Prog Technol 9(209):215, 1983.

9. Rosen MJ, Goodenough-Trepagnier C, Dalrymple G, Miller J: Computer-aided assessment for communication rate prediction. In Proceedings of the 7th Annual IEEE EMBS Conference, Chicago, 1985.

10. Rosen MJ, Goodenough-Trepagnier C, Miller J, Dalrymple G, Jandura L, Getschow C, Leung S, Lee $\mathrm{S}$ : Computer-aided motor assessment and rate prediction for prescription of communication devices. In Proceedings of 8th Annual Conference on Rehabilitation Technology, Memphis, 326-328, 1985.
11. Rosen MJ, Goodenough-Trepagnier C: The Tufts-MIT prescription guide: Assessment of users to predict the suitability of augmentative communication devices. Assist Technol 1(3):51-61, 1989.

12. Shaver MS: Retrospective study of electronic technical aid use among high-level quadriplegic males. In Electronic Technical Aid for Persons with Severe Physical Disabilities, R. Dickey (Ed.), Rusk Institute of Rehabilitative Medicine, New York, 1985.

13. Turoff M: The Policy Delphi. In The Delphi Method: Techniques and Applications, H.A. Linstone and M. Turoff (Eds.), Reading, MA: Addison-Wesley, 1985.

14. Vash CL: Psychological aspects of rehabilitation engineering. In Technology for Independent Living-Proceedings from the 1981 Workshops on Science and Technology for the Handicapped, AAAS, 1983. 